\title{
Canine Lymphoma
}

National Cancer Institute

\section{Source}

National Cancer Institute. Canine Lymphoma. NCI Thesaurus. Code C128121.

A malignant lymphoproliferative disorder that affects dogs. It is characterized by the clonal proliferation of B- or T-lymphocytes in the lymph nodes, bone marrow, and/or extranodal sites. 